\title{
IMPLEMENTASI ALGORITMA FUZZY EVOLUSI UNTUK PENGATURAN JADWAL LABORATORIUM KOMPUTER DI SEKOLAH
}

\section{IMPLEMENTATION OF EVOLUTION FUZZY ALGORITHM FOR SCHOOL LABORATORY SCHEDULING MANAGEMENT}

\author{
Luqman Abdul Malik ${ }^{1}$ \\ Elkaf Rahmawan Pramudya ${ }^{2}$ \\ Teknik Informatika Fakultas Ilmu Komputer Universitas Dian Nuswantoro ${ }^{1,2}$ \\ E-mail : 111201105889@mhs.dinus.ac.id ${ }^{1}$, elkaf.rahmawan@dsn.dinus.ac.id ${ }^{2}$
}

Diterima: 5 Juni 2017/ Disetujui : 12 Juni 2017

\begin{abstract}
Problems in the placement of the clock and the use of the computer lab this time wearing schedule which already available, but the use of spaces and their subjects will use laboratory space is not yet available on the schedule of lessons. This is a constraint in the use of computer lab room each day and happens constantly every day and every week. But yet the formation schedule use of a computer lab space evenly for classes which does require a competence in practice the subjects and rely solely on coming first entered in the computer lab. Scheduling the use of the computer lab is expected to obtain a schedule by the number of hours of instruction that are already defined and a timetable of the lessons taught are evenly distributed to every teacher lessons and students can be met to use the computer lab right on schedule in order not to occur collisions. In the fuzzy algorithm of evolution has several stages, among others: Represent chromosome, Initialize the population, Determining the function of Evaluation, doing the selection, Specify the Operator and include a combination of genetics, in the crossover and mutation.
\end{abstract}

Key words: genetic algorithms, scheduling systems, evolution fuzzy algorithm

\begin{abstract}
ABSTRAK
Penyusunan jadwal mengajar untuk saat ini masih manual atau berupa file excel dan dirundingkan antara kepala sekolah dan wakil kepala kurikulum. Masalah dalam penempatan jam dan penggunaan laboratorium komputer saat ini memakai jadwal yang sudah tersedia, tetapi penggunaan ruang beserta mata pelajaran yang akan menggunakan ruang laboratorium belum tersedia sesuai jadwal pelajaran. Hal ini menjadi kendala dalam penggunaan ruang laboratorium komputer.Tetapi belum terbentuknya jadwal penggunaan ruang laboratorium komputer secara merata untuk kelas-kelas yang memang membutuhkan praktik pada kompetensi mata pelajaran tersebut dan hanya mengandalkan datang lebih dahulu masuk dalam laboratorium komputer. Penjadwalan penggunaan laboratorium komputer ini diharapkan dapat memperoleh jadwal dengan jumlah jam pelajaran yang sudah ditentukan dan jadwal pelajaran mengajar yang merata untuk setiap guru pelajaran dan siswa dapat terpenuhi untuk menggunakan laboratorium komputer sesuai jadwal agar tidak terjadi benturan. Suatu
\end{abstract}


metode yang menggabungkan antara algoritma genetika dengan sistem fuzzy di kenal sebagai algoritma fuzzy evolusi, tetapi metode ini memiliki persamaan dengan algoritma genetika.Tetapi dengan sistem fuzzy yang menggunakan parameter-parameter untuk mendapatkan hasil. Dalam algoritma fuzzy evolusi memiliki beberapa tahap antara lain : Merepresentasikan kromosom, Menginisialisasi Populasi, Menentukan Fungsi Evaluasi, Melakukan Seleksi, Menentukan Operator genetika, dan meliputi kombinasi ulang pada (crossover) dan mutasi.

Kata kunci : sistem penjadwalan, algoritma genetika, algoritma fuzzy evolusi

\section{PENDAHULUAN}

SMK Alfattaah Boarding School Demak memiliki jurusan Multimedia (MM) dan Teknik Kendaraan Ringan(TKR).Jumlah keseluruhan siswa adalah 266 siswa dan jumlah guru adalah 26 orang. Kemudian Guru produktif (multimedia) ada 4 orang dengan kompetensi yang berbeda beda, ada 11 mata pelajaran dan total jam keseluruhan 78 jam dan mengajarnya ada yang sama dalam satu hari dan jam yang sama sesuai dengan permintaan guru. Pada SMK Alfattaah Boarding School Demak memiliki satu ruang laboratorium komputer yang terdiri dari 1(satu) unit komputer server dan 32(tiga puluh dua) unit komputer client.Setiap tahun pelajaran baru, kegiatan belajar mengajar di SMK Alfattaah Boarding School Demak, selalu menggunakan jadwal belajar mengajar yang baru dan tiap semester berbeda kompetensi. Hal ini menjadi kendala dalam penyusunan jadwal jam pelajaran yang meliputi permintaan salah satu guru mata pelajaran untuk dapat mengajar sesuai kehendak guru dalam hari dan jam tertentu.Penyusunan jadwal mengajar untuk saat ini masih manual atau berupa fileexcel dan dirundingkan antara kepala sekolah dan waka kurikulum. Masalah dalam penempatan jam dan penggunaan laboratorium komputer saat ini memakai jadwal yang sudah tersedia, tetapi penggunaan ruang beserta mata pelajaran yang akan menggunakan ruang laboratorium belum terakomodasikan sesuai jadwal pelajaran. Dalam hal ini maka penggunaan laboratorium komputer masih bergantian antara guru satu dengan guru yang lain dan salah satu guru hanya bisa menggunakan ruang kelas jika ruang laboratorium sudah digunakan kelas lain dan bergantian untuk minggu depannya.Dalam SMK Alfattaah Boarding School Demak, setiap harinya total waktu pelajaran dalam sehari adalah 8 jam pelajaran. Kemudian pada hari senin jam ke-2 dan ke-3 pelajaran design grafis untuk kelas X Multimedia, dan dalam waktu yang sama kelas XI Multimedia 1 pelajaran Mengoperasikan software digital video pada jam ke-2 dan ke-3, hal ini bertepatan pelajaran yang membutuhkan praktik di ruang laboratorium komputer. Kemudian jam ke-4 sampai jam ke-6 pelajaran mengelola halaman web pada kelas XI Multimedia 1 juga berbenturan dengan kelas XII Multimedia 1 di jam yang sama pelajaran Menggabungkan audio kedalam multimedia. Untuk jam ke-7 sampai ke-8 kelas X Multimedia pelajaran membuat storyboard aplikasi multimedia berbenturan dengan jam yang sama kelas XII Multimedia 1 pelajaran Menerapkan efek khusus pada objek produksi.Hal ini menjadi kendala dalam penggunaan ruang laboratorium komputer setiap harinya dan terjadi terus-menerus setiap hari dan setiap minggu.Maka diharapkan mendapat solusi untuk memecahkan masalah tersebut.Untuk kegiatan belajar mengajar saat ini masih berjalan normal menggunakan jadwal pelajaran mengajar, tetapi belum terbentuknya jadwal penggunaan ruang laboratorium komputer secara merata untuk kelas-kelas yang memang membutuhkan praktik pada kompetensi mata pelajaran tersebut dan hanya mengandalkan datang lebih dahulu masuk dalam laboratorium komputer. 


\section{METODE PENELITIAN}

Suatu teknik komputasi yang menggabungkan genetic algorithm [1] dengan fuzzy systemdisebut sebagai evolution fuzzy algorithm [2]. Sistem fuzzy ini juga memiliki kesamaan dengan algoritma genetika, tetapi sistem fuzzy ini memiliki parameter-parameter yang akan digunakan untuk mendapatkan hasil [3]. Berikut tahapan algoritma fuzzy evolusi yang memiliki persamaan dengan tahapan algoritma genetika, yaitu $[4,5,6]$ :

1. Merepresentasikan kromosom.

2. Menginisialisasi Populasi.

3. Melakukan Fungsi evaluasi.

4. Melakukan Seleksi.

5. Operator genetika, meliputi operator rekombinasi (crossover) dan mutasi.

Untuk menentukan nilai parameter, dengan melakukan pengendalian pada parameter algoritma genetika [7][8], seperti: ukuran pada peluang crossover (pc), peluang mutasi (pm) dan populasi (popsize). Proses di lakukan oleh sistem fuzzy agar menghasilkan parameter yang terdiri dari nilai.

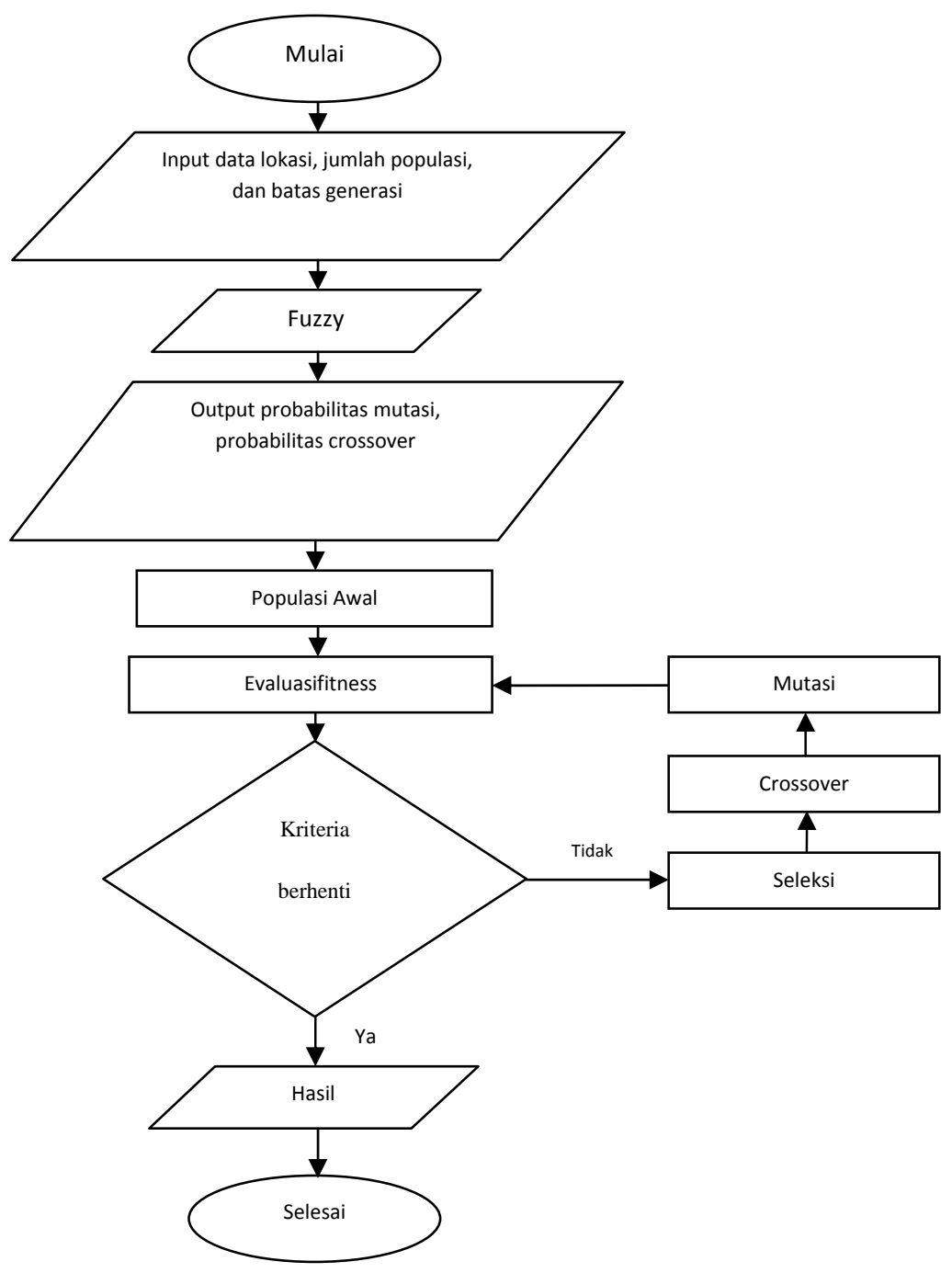

Gambar 1. Flowcart fuzzy evolusi 
1. Jachwal penggunoan laboratorium komputer belum dibuat dapat dilinat dilatar belakming maskakah.

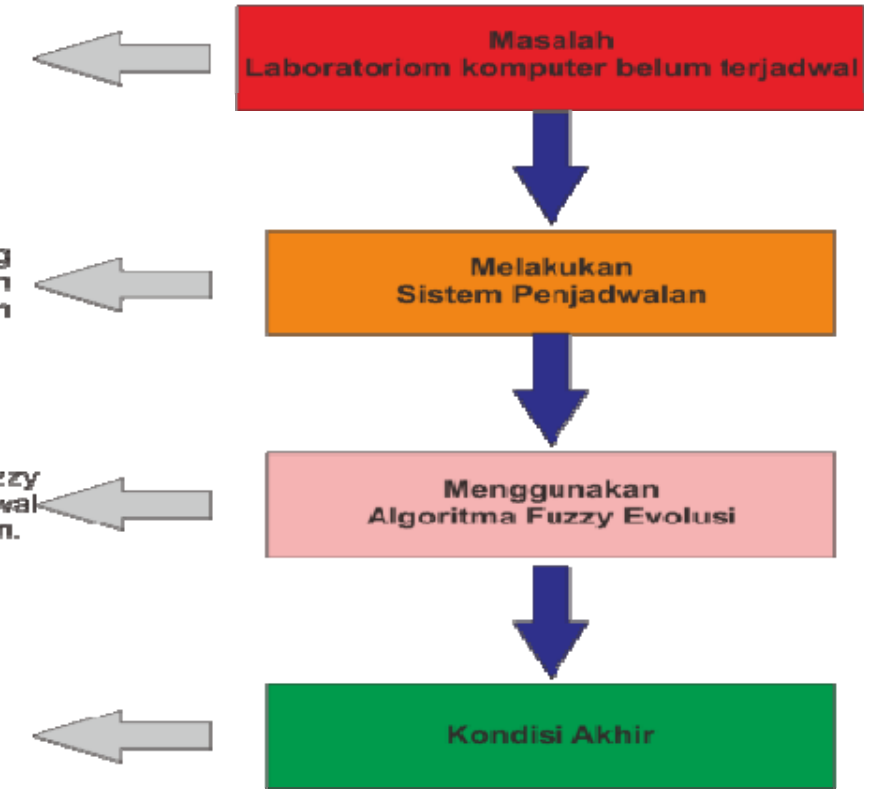

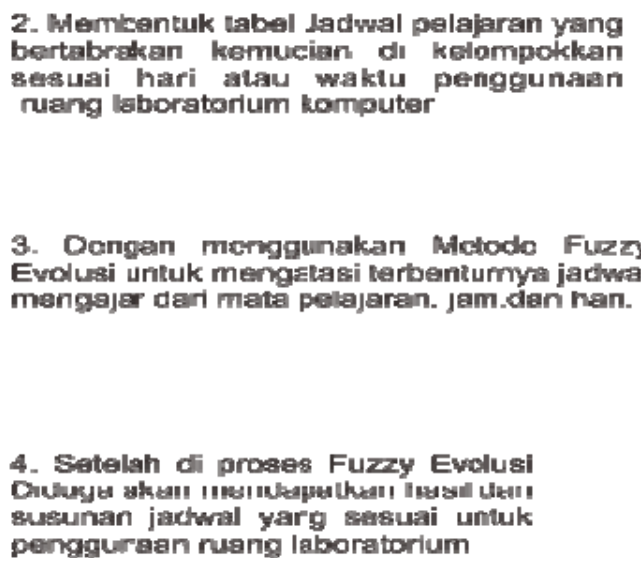

4. Setelah di proses Fuzzy Evolus:

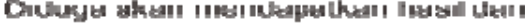
susunan jacharal yarg sessuai umtuk pengguraan nuang laboratorium

Gambar 2. Kerangka Pemikiran

Adapun cara untuk melakukan pengujian pada Algoritma Fuzzy Evolusi, yaitu :

1. Representasi Kromosom

Menentukan data, seperti : kode mata pelajaran, kode guru, kode sebaran jam, kode ruang pada smk alfattaah demak.

2. Inisialisasi populasi

Menentukan pembentukan kromosom yg berisikan nama mata pelajaran, nama guru, waktu dan ruang.

\section{Fungsi evaluasi}

Benturan antara guru dan waktu, maka fungsi objektif yang dapat digunakan agar memperoleh solusi adalah fungsi_objektif = banyaknya bentrok guru dan waktu antara satu kromosom dengan kromosom lainnya

\section{Seleksi}

Untuk memilih individu-individu mana saja yangakan dipilih untuk proses crossover dan mutasi.untuk penyelesaian permasalahan benturan pada penjadwalan perkuliahan adalah metode seleksi roda roulette.

$$
F_{i}=\frac{1}{1+\text { iftungst_obfeket } f(\text { kromarom }))}
$$

Selanjutnya dihitung nilai kumulatif probabilitas sebanyak kromosom yang ada, misal seperti bawah ini :

$$
\begin{aligned}
& \text { Kumulatif } f_{1}=0,167 \\
& \text { Kumulatif } 2=0,167+0,167=0,333
\end{aligned}
$$

\section{Crossover}

Untuk menghasilkan offspring menjadi individu untuk populasi berikutnya maka Crossover melakukan persilangan sepasang kromosom orang tua.Yang diharapkan dapat mewarisi sifat sifat unggul yang dimiliki kromosom orang tua.Order Crossover yaitu perpindahan silang pada 
suatu masalah jalur paling pendek ini. Penentuan parameter probabilitas crossover memengaruhi pada banyaknya kromosom yang akan di persilangkan (crossover).

Setelah Offstring dapat terbentuk dari proses Crossover maka langkah selanjutnya adalah melakukan validasi pada jalur yang terdapat didalamnya, kemungkinan Offstring sudah terbentuk dapat direpresentasikan pada jalur tidak valid.

6. Mutasi

Suatu proses dalam melakukan pertahanan pada keanekaragaman populasi genetika yang disebut Mutasi. Hal ini dapat melakukan pencegahan populasi agar tidak terjebak pada solusi optimal local.

Untuk memulai proses mutasi maka daftar hasil baru populasi Crossover dipilih secara acak untuk dilibatkan. Pada proses seleksi atau pengembalian kromosom optimal yang hilang akibat proses persilangan (crossover) dikarenakan pada penggantian gen yang hilang dari populasi dan hal ini merupakan peranan penting dari mutasi. Dan kemungkinan akan muncul yang lebih baik dari kromosom pada populasi kromosom yang tidak ditampilkan pada populasi awal.

7. Pembentukan Populasi Untuk Generasi Berikutnya

Pada langkah pertama untuk penentuan pilihan individu sebagai generasi berikutnya maka di lakukanlah penggabungan pada semua kromosom orang tua dengan semua kromosom anak maupun yang mengalami mutasi ataupun tidak mengalami mutasi. Selanjutnya menghitung nilai fitness pada penggabungan kromosom tersebut.Kemudian melakukan pengurutan pada kromosom dari fitness paling tinggi sampai paling rendah.Langkah terakhir yaitu mengambil kromosom yang mempunyai nilai fitness paling tinggi sebanyak ukuran populasi yang sudah ditentukan pada diawal.

8. Kriteria Berhenti

Untuk mencapai suatu kriteria berhenti maka dilakukan proses pada algoritma genetika yang akan berulang-ulang sampai mencapainya dan akan berhenti setelah mencapai penentuan batas generasi. Maka, kriteria akan berhenti melakukan pencarian jalur terpendek ini disebut generations.

\section{HASIL DAN PEMBAHASAN}

Perhitungan dan penentuan data penelitian menggunakan algoritma fuzzy evolusi.

\subsection{Reprentasi Kromosom}

Permasalahan yang akan diselesaikan adalah benturan yang terdapat pada penjadwalan mata pelajaran maka dibentuk tabel jadwal mata pelajaran sebagai berikut :

\subsection{Inisialisasi populasi}

Untuk memudahkan pembentukan kromosom, nama mata kuliah, nama guru, waktu, dan r uangan diberi kode yang terdapat pada Tabel 4.2 hingga Tabel 4.5 . 
Tabel 1. Kode Sebaran Mata Pelajaran

\begin{tabular}{|c|c|}
\hline $\begin{array}{c}\text { Kode } \\
\text { Mata } \\
\text { Pelajaran }\end{array}$ & Nama Mata Pelajaran \\
\hline 14 & Memahami alir proses produksi produk multimedia \\
\hline 15 & Merawat peralatan computer \\
\hline 16 & Menerapkan teknik pengambilan gambar produksi \\
\hline 17 & Memahami cara penggunaan peralatan tata cahaya \\
\hline 18 & Membuat storyboard aplikasi multimedia \\
\hline 19 & Mengelola isi halaman web \\
\hline 20 & Mengoperasikan software digital video \\
\hline 21 & Menguasai dasar animasi stopmotion bidang datar \\
\hline 22 & Menggabungkan fotografi digital kedalam sajian multimedia \\
\hline 23 & Menggabungkan audio kedalam multimedia \\
\hline 24 & Menerapkan efek khusus pada objek produksi \\
\hline 39 & Design grafis \\
\hline 8 & KKPI \\
\hline
\end{tabular}

Tabel 2. Kode Guru

\begin{tabular}{|c|l|}
\hline $\begin{array}{c}\text { Kode } \\
\text { Guru }\end{array}$ & \multicolumn{1}{|c|}{ Nama Guru } \\
\hline $\mathrm{H}$ & Achmad Bachtiar, S.Si \\
\hline $\mathrm{M}$ & Erlin Wahyu Timor Tiningsih, ST \\
\hline $\mathrm{R}$ & Abdul Azis, S. Kom \\
\hline $\mathrm{S}$ & Fatkhur Rokhim,S.Kom \\
\hline $\mathrm{X}$ & Ma'ruf Hidayatullah \\
\hline
\end{tabular}


Tabel 3. Kode Sebaran Hari

\begin{tabular}{|c|c|}
\hline Kode/Jam & Hari \\
\hline $1 \mathrm{H}$ & SENIN \\
\hline $2 \mathrm{H}$ & SELASA \\
\hline $3 \mathrm{H}$ & RABU \\
\hline $4 \mathrm{H}$ & KAMIS \\
\hline $5 \mathrm{H}$ & JUM'AT \\
\hline $6 \mathrm{H}$ & SABTU \\
\hline
\end{tabular}

Tabel 4. Kode Sebaran Waktu

\begin{tabular}{|c|c|}
\hline Kode/Jam & Waktu \\
\hline A1 & $07.00-07.45$ \\
\hline A2 & $07.45-08.30$ \\
\hline A3 & $08.30-09.15$ \\
\hline A4 & $09.30-10.15$ \\
\hline A5 & $10.15-11.00$ \\
\hline A6 & $11.00-11.45$ \\
\hline A7 & $12.00-12.45$ \\
\hline A8 & $12.45-13.30$ \\
\hline A9 & $08.00-09.30$ \\
\hline A10 & $09.45-10.30$ \\
\hline A11 & $10.30-11.15$ \\
\hline
\end{tabular}

Tabel 5. Kode Ruangan

\begin{tabular}{|c|c|}
\hline Kode Ruang & Ruang Kelas \\
\hline LAB1 & Lab Komputer 1 \\
\hline
\end{tabular}


Dari tabel-tabel di atas dapat dibentuk 6 kromosom yang terdiri dari kode mata pelajaran, kode guru, kode waktu dan kode ruangan.

Maka kromosom yang dapat dibentuk adalah sebagai berikut :

Kromosom1 = 39R 1H A2A3 LAB1

Kromosom2 = 20H 1H A2A3 LAB1

Kromosom3 = 19H 1H A4A5A6 LAB1

Kromosom4 = 23R 1H A4A5A6 LAB1

Kromosom5 = 18R 1H A7A8 LAB1

Kromosom6 = 24H 1H A7A8 LAB1

\subsection{Fungsi Evaluasi}

Permasalahan yang akan diselesaikan adalah permasalahan mengenai benturan antara guru, waktu dan ruang, maka fungsi objektif yang dapat digunakan agar memperoleh solusi adalah fungsi_objektif = banyaknya bentrok guru, waktu dan ruang antara satu kromosom dengan kromosom lainnya.

$$
\begin{aligned}
& \text { Fungsi_Objektif(Kromosom 1)=1 } \\
& \text { Fungsi_Objektif(Kromosom 2)=1 } \\
& \text { Fungsi_Objektif(Kromosom 3)=1 } \\
& \text { Fungsi_Objektif(Kromosom 4)=1 } \\
& \text { Fungsi_Objektif(Kromosom 5)=1 } \\
& \text { Fungsi_Objektif(Kromosom 6) }=1
\end{aligned}
$$

\subsection{Seleksi}

Proses seleksi digunakan untuk memilih individu - individu mana saja yangakan dipilih untuk proses crossover dan mutasi. Metode seleksi yang dipilihuntuk penyelesaian permasalahan benturan pada penjadwalan mata pelajaran adalah metode seleksi roda roulette. Langkah pertama dari metode seleksi roda roulette adalah menghitung nilai fitness, dimana rumusan fungsinya sebagai berikut :

$$
E_{i}=\frac{1}{1+(f \mathrm{umgst} e \text { bfekttf }(\text { kromosomp) }}
$$

Dari rumusan fungsi di atas diperoleh nilai fitness untuk masing-masing kromosom adalah
masing-masing
0,5 .
Dengan
total
nilai
fitness
$=0,5+0,5+0,5+0,5+0,5+0,5+0,5+0,5+0,5+0,5+0,5+0,5+0,33+0,33+0,33+0,5+0,5+0,33+0,33+0,33+0$, 
$5+0,5+0,33+0,33+0,33+0,5+0,5+0,5+0,5=13$. Selanjutnya dihitung probabilitas setiap kromosom dengan tiap probabilitas menghasilkan 0,038.Selanjutnya dihitung nilai kumulatif probabilitasnya :

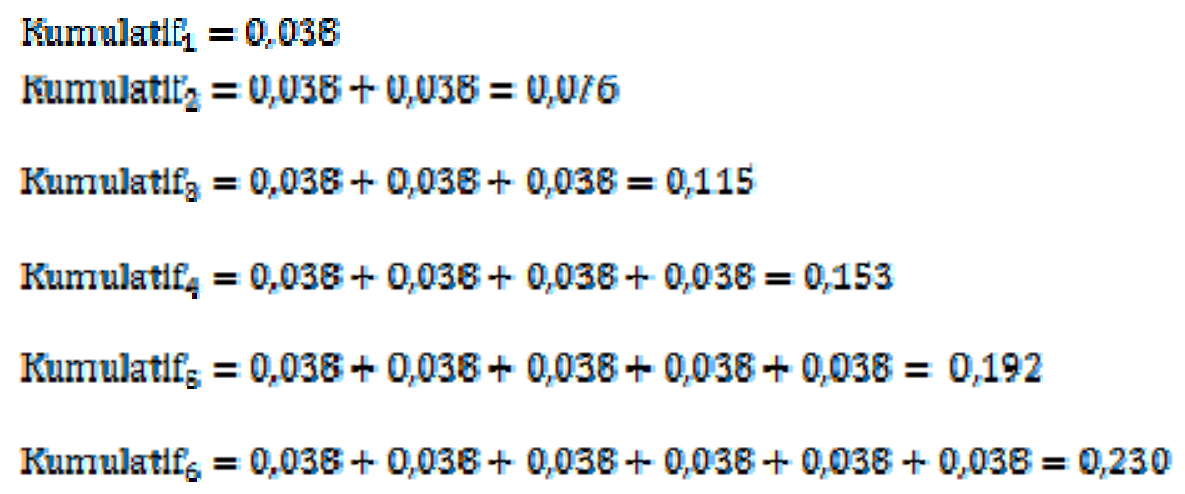

Setelah dihitung nilai kumulatif probabilitas dari masing-masing kromosom maka selanjutnya adalah membangkitkan bilangan acak $\mathrm{R}$ dalam range [0 - 1].

Tabel 6. Kromosom, probabilitas kumulatif dan pembangkitan bilangan acak

\begin{tabular}{|c|c|c|}
\hline $\begin{array}{c}\text { Kromos } \\
\text { om }\end{array}$ & $\begin{array}{l}\text { Probabilit } \\
\text { as } \\
\text { Kumulatif }\end{array}$ & $\begin{array}{c}\text { Bilangan } \\
\text { Acak(rand } \\
\text { om })\end{array}$ \\
\hline R[1] & 0,038 & 0,343 \\
R[2] & 0,076 & 0,635 \\
R[3] & 0,115 & 0,527 \\
R[4] & 0,153 & 0,284 \\
R[5] & 0,192 & 0,711 \\
R[6] & 0,230 & 0,692 \\
\hline
\end{tabular}

Selanjutnya bilangan random yang telah di bangkitkan tentukan pada kromosom mana bilangan random tersebut berada. Dengan rumus jika bilangan acak $\mathrm{R}[1] \leq 0$ dan $\leq$ Nilai Probabilitas Kumulatif $_{1} \leq 0,038$ maka terbentuk kromosom baru yang terpilih adalah komosom 1 begitu seterusnya. Sehingga didapatkan kromosom baru hasil seleksi adalah :

Kromosom[1] =>Kromosom[9] = 8R 2H A3A4 LAB1

Kromosom[2] =>Kromosom[18]= 15S 5H A9 LAB1

Kromosom[3] =>Kromosom[15] $=8$ M 4H A1A2 LAB1

Kromosom[4] =>Kromosom[8] = 20H 2H A1A2 LAB1

Kromosom[5] =>Kromosom[21] = 8X 5H A10 LAB1

Kromosom[6] =>Kromosom[20]= 24H 5H A9 LAB1 


\subsection{Penentuan parameter menggunakan fuzzy dengan Tools Matlab}

Dengan melakukan percobaan untuk jumlah populasi 50 dan jumlah generasi 100, dengan fungsi keanggotaan populasi dan fungsi keanggotaan generasi. Maka di dapatkan aturan - aturan untuk penentuan parameternya, berikut proses dalam Matlab menghasilkan Nilai Probabilitas Crossover $=0,867$ dan Nilai Probabilitas Mutasi $=0,133$.

\subsection{Crossover}

Setelah proses seleksi kromosom maka kromosom-kromosom dengan kemungkinan fitness terbaik terpilih, langkah selanjutnya adalah melakukan crossover atau kawin silang. Dalam penelitian ini crossover dilakukan dengan One-Cut Point yakni dengan memilih satu gen secara acak pada kromosom pertama dan kemudian ditukar dengan gen pada kromosom yang lain.

Kromosom[1] =>Kromosom[9] = 8R 2H A3A4 LAB1

Kromosom[2] =>Kromosom[18]= 15S 5H A9 LAB1

Kromosom[3] =>Kromosom[15] $=8$ M 4H A1A2 LAB1

Kromosom[4] =>Kromosom[8]= 20H 2H A1A2 LAB1

Kromosom[5] =>Kromosom[21] = 8X 5H A10 LAB1

Kromosom[6]=>Kromosom[20]= 24H 5H A9 LAB1

Langkah selanjutnya membangkitkan bilangan acak R dalam range [0 - 1].Dengan Probabilitas Crossover 0,867.

Tabel 7. Hasil Pembangkitan Bilangan Acak

\begin{tabular}{|c|c|}
\hline $\begin{array}{c}\text { Kromoso } \\
\mathrm{m}\end{array}$ & Random $[0-1]$ \\
\hline $\mathrm{R}[1]$ & 0,936 \\
$\mathrm{R}[2]$ & 0,547 \\
$\mathrm{R}[3]$ & 0,912 \\
$\mathrm{R}[4]$ & 0,875 \\
$\mathrm{R}[5]$ & 0,967 \\
$\mathrm{R}[6]$ & 0,673 \\
\hline
\end{tabular}

Kemudian bandingkan Ri dengan Probabilitas_CrossoverdimanaProbabilitas_Crossover yang diperoleh dari sistem inferenzi fuzzy sebesar 0,867. Apabila $\mathrm{Ri}<$ Probabilitas_Crossover maka kromosom tersebut direkombinasi (crossover). Dari bilangan random yang telah dibangkitkan, 
memperoleh, kromosom 2, dan kromosom 6 yang akan direkombinasi (crossover) dan gen yang akan direkombinasikan adalah gen waktu atau jam, maka gen waktu kromosom dari induk pertama diambil kemudian ditukar dengan gen waktu pada kromosom induk kedua.

Berikut contoh penyelesaiannya :

Kromosom[2] = Kromosom[18] X Kromosom[2]= 15S 5H A9 LAB1 X 20H 1H A2A3 LAB1= 15S

5H A2A3 LAB1

Kromosom[6] = Kromosom[20] X Kromosom[6]= 24H 5H A9 LAB1 X 24H 1H A7A8 LAB1=24H 5H A7A8 LAB1

Sehingga didapatkan kromosom baru setelah di crossover.

Kromosom[1] = 8R 2H A3A4 LAB1

Kromosom[2] = 15S 5H A2A3 LAB1

Kromosom[3] = 8M 4H A1A2 LAB1

Kromosom[4] = 20H 2H A1A2 LAB1

Kromosom[5] = 8X 5H A10 LAB1

Kromosom[6] = 24H 5H A7A8 LAB1

\subsection{Mutasi}

Mutasi dilakukan dengan memilih sembarang kromosom biasanya dilakukan secara acak dan kemudian memilih gen pada kromosom yang akan dimutasi, prosesnya adalah mengubah nilai pada gen dengan nilai yang baru sehingga memungkinkan perubahan gen yang akan mengarah pada fitness yang lebih baik pada kromosom. Langkah pertama yang harus dilakukan adalah menghitung panjang total gen. Panjang total gen $=$ jumlah gen dalam 1 kromosom * jumlah kromosom. Panjang total gen = $2 * 6=12$. Probabilitas mutasi yang di peroleh sistem fuzzy adalah 0,133 . Sehingga jumlah gen yang akan mengalami perubahan mutasi $=12 * 0,133=1,596$ dibulatkan $=2$ gen yang akan mengalami mutasi. Kemudian 2 buah gen tersebut akan di mutasi setelah di acak adalah gen ke-3 dan gen ke-4. Dengan demikian yang akan mengalami mutasi adalah gen hari pada kromosom [3] di mutasi ke kromosom [6]. Sehingga didapatkan populasi setelah proses mutasi adalah :

Berikut hasil mutasi pada penelitian ini dapat dilihat pada dibawah ini :

Kromosom[1] = 8R 2H A3A4 LAB1

Kromosom[2] $=15 \mathrm{~S} 5 \mathrm{H}$ A2A3 LAB1

Kromosom[3] = 8M 4H A1A2 LAB1 
Kromosom[4] = 20H 2H A1A2 LAB1

Kromosom[5] = 8X 5H A10 LAB1

Kromosom[6] = 24H 4H A7A8 LAB1

3.8. Pembentukan Populasi Untuk Generasi Berikutnya

Setelah keenam langkah tersebut dilakukan, diperoleh kromosom akhir sebagai berikut :

Kromosom[1] = 8R 2H A3A4 LAB1

Kromosom[2] = 15S 5H A2A3 LAB1

Kromosom[3] = 8M 4H A1A2 LAB1

Kromosom[4] = 20H 2H A1A2 LAB1

Kromosom[5] $=$ 8X 5H A10 LAB1

Kromosom[6] = 24H 4H A7A8 LAB1

Kemudian dicari kembali nilai fitness setelah 1 generasi, yaitu menghasilkan masing-masing 1.Karena kondisi penghentian algoritma telah terpenuhi yaitu seluruh kromosom memiliki nilai fitness satu. Hal tersebut menandakan bahwa pada penjadwalan sudah tidak terdapat benturan maka proses penggenerasian menggunakan algoritma fuzzy evolusi dapat dihentikan.

Sehingga jadwal kuliah yang mengalami perubahan jadwal adalah sebagai berikut :

Tabel 8. Hasil Jadwal Kuliah

\begin{tabular}{|c|c|c|c|c|c|c|}
\hline \multirow{2}{*}{ Hari } & \multirow{2}{*}{ Waktu } & \multirow{2}{*}{ Kelas } & \multicolumn{2}{|c|}{ Mata Pelajaran } & \multicolumn{2}{|r|}{ Guru } \\
\hline & & & Kode & Nama & Kode & Nama \\
\hline SELASA & $\begin{array}{c}08.30- \\
10.15\end{array}$ & X MM & 8 & KKPI & $\mathrm{R}$ & $\begin{array}{l}\text { Abdul Azis, } \\
\text { S.Kom }\end{array}$ \\
\hline JUM'AT & $\begin{array}{c}07.45- \\
09.15\end{array}$ & X MM & 15 & $\begin{array}{c}\text { Merawat peralatan } \\
\text { komputer }\end{array}$ & $\mathrm{S}$ & $\begin{array}{c}\text { Fatkhur } \\
\text { Rokhim,S.Kom }\end{array}$ \\
\hline KAMIS & $\begin{array}{c}07.00- \\
08.30\end{array}$ & $\begin{array}{c}\text { XII MM } \\
1\end{array}$ & 8 & KKPI & $\bar{M}$ & $\begin{array}{c}\text { Erlin Wahyu } \\
\text { TT,ST }\end{array}$ \\
\hline SELASA & $\begin{array}{c}07.00- \\
08.30\end{array}$ & $\begin{array}{c}\text { XI MM } \\
1\end{array}$ & 20 & $\begin{array}{l}\text { Mengoperasikan } \\
\text { software digital }\end{array}$ & $\mathrm{H}$ & $\begin{array}{c}\text { Achmad Bachtiar, } \\
\text { S.Si }\end{array}$ \\
\hline JUM'AT & $\begin{array}{c}09.45- \\
10.30\end{array}$ & $\begin{array}{l}\text { XI MM } \\
2,\end{array}$ & 8 & KKPI & $\mathrm{X}$ & $\begin{array}{c}\text { Ma'ruf } \\
\text { Hidayatullah }\end{array}$ \\
\hline
\end{tabular}




\begin{tabular}{|c|c|c|c|c|c|c|}
\hline & & $\begin{array}{l}\text { XI TKR } \\
2\end{array}$ & & & & \\
\hline KAMIS & $\begin{array}{c}12.00- \\
13.30\end{array}$ & $\begin{array}{c}\text { XII MM } \\
1\end{array}$ & 24 & $\begin{array}{c}\text { Menerapkan efek } \\
\text { khusus pada objek } \\
\text { produksi }\end{array}$ & $\mathrm{H}$ & $\begin{array}{c}\text { Achmad Bachtiar, } \\
\text { S.Si }\end{array}$ \\
\hline
\end{tabular}

\section{KESIMPULAN}

Dengan diterapkannya Konsep fuzzy pada algoritma fuzzy evolusi untuk penentuan parameter pada algoritma genetika seperti probabilitas crossover dan probabilitas mutasi.Sistem fuzzy yang digunakan pada algoritma fuzzy evolusi adalah sistem inferensi fuzzy Tsukamoto. Sistem ini dapat menghasilkan probabilitas crossover dan probabilitas mutasi yang pasti dibandingkan dengan percobaan berulang-ulang menggunakan probabilitas crossover dan probabilitas mutasi yang samar. Dan dapat menyelesaikan permasalahan benturan pada sistem penjadwalan penggunaan laboratorium komputer dengan cara mengubah jadwal pelajaran ke dalam bentuk kromosom. Kemudian dicek apakah ada kromosom ada yang sama atau tidak, jika terdapat kromosom yang sama maka pada penjadwalan tersebut terdapat benturan. Kemudian kromosom tersebut akan melalui proses algoritma genetika, yaitu perhitungan nilai fitness, seleksi, crossover, dan mutasi. Pada saat proses crossover, dan mutasi dibutuhkan probabilitas crossover dan probabilitas mutasi yang diperoleh dari proses fuzzy. Proses fuzzy yang digunakan pada penelitian ini menggunakan sistem inferensi fuzzy Tsukamoto yang menggunakan dua buah masukan dan menghasilkan dua buah keluaran. Dua buah masukkan tersebut adalah jumlah populasi dan jumlah generasi sedangkan dua buah keluaran yang diperoleh adalah probabilitas crossover dan probabilitas mutasi.

\section{SARAN}

Untuk lebih mengoptimalkan hasil penelitian ini, maka beberapa hal yang perlu dikembangkan untuk penelitian selanjutnya adalah :

1. Dengan menentukan jumlah populasi dan jumlah generasi yang tepat maka untuk menyelesaikan permasalahan tersebut tidak perlu percobaan berulang-ulang untuk mendapatkan hasil yang diharapkan.

2. Dapat mengembangkan ke dalam aplikasi berbasis GUI (Graphical User Interface) dan dapat menyelesaikan permasalahan benturan antara ruang dan waktu dan permasalahan lainnya yang akan muncul pada penjadwalan.

\section{DAFTAR PUSTAKA}

[1] Yuwaffa Almas Akbar, "Optimasi Penjadwalan Dengan Metode Algoritma Genetika "Steady State” Studi Kasus Penjadwalan Ruang Laboratorium Di Smp Negeri 1 Bulu Temanggung", Skripsi Teknik Informatika Universitas Dian Nuswantoro, Semarang, 2013.

[2] Herny Wulandari Pangestu, "Implementasi Algoritma Fuzzy Evolusi Pada Penjadwalan Perkuliahan", Skripsi Fakultas Pendidikan Matematika Dan Ilmu Pengetahuan Alam Universitas Pendidikan Indonesia, Bandung, 2015.

[3] Setyoningsih Wibowo, "Penerapan Logika Fuzzy Dalam Penjadwalan Waktu Kuliah”, Jurnal Informatika Universitas PGRI Semarang, Volume 1 Edisi Juni 2015. 
[4] Wahyu Setiawati, "Sistem Penjadwalan Mata Kuliah BerdasarkanPeminatan Mahasiswa Menggunakan Metode Asosiasi Yang Disempurnakan Dengan Algoritma Genetika”, Jurnal Informatika Universitas Dian Nuswantoro Semaranag, 2015.

[5] Ida Bagus Putra Manuaba, S.Kom, "Sistem Penjadwalan Produksi Menggunakan Metode Fuzzy Support Vector Machines dan Algoritma Evolusi Fuzzy”, Jurnal Prosiding Conference on SmartGreen Technology in Electrical and Information Systems. UniversitasUdayana Bali, 2013.

[6] Edi Sugiarto, Sri Winarno, Amiq Fahmi, "Penjadwalan Perkuliahan Otomatis Berbasis Fuzzy Logic Dan Genetic Algorithm Pada Universitas Dian Nuswantoro”, Jurnal Techno.COM, Vol. 14, No. 4, November 2015.

[7] Arief Kelik Nugroho, "Penerapan Algoritma Genetika Untuk Menyelesaikan Permasalahan Penjadwalan Dosen Dengan Fuzzy”, Jurnal Fakultas Teknik, Universitas PGR Yogyakarta, 2014.

[8] Nia Kurnia Mawaddah, Wayan Firdaus Mahmudy, "Optimasi Penjadwalan Ujian Menggunakan Algoritma Genetika”, Jurusan Matematika, FMIPA Universitas Brawijaya, 2006. 